\title{
A New System to Evaluate Comprehensive Performance of Hard-Rock Tunnel Boring Machine Cutterheads
}

\author{
Ye Zhu ${ }^{1 *}$, Wei Sun², Junzhou Huo ${ }^{2}$ and Zhichao Meng ${ }^{2}$
}

\begin{abstract}
The accurate performance evaluation of a cutterhead is essential to improving cutterhead structure design and predicting project cost. Through extensive research, this paper evaluates the performance of a tunnel boring machine (TBM) cutterhead for cutting ability and slagging ability. This paper propose cutting efficiency, stability, and continuity of slagging as the evaluation indexes of comprehensive cutterhead performance. On the basis of research of true TBM engineering applications, this paper proposes a calculation method for each index. A slagging efficiency index with a ratio of the maximum difference between the slagging amount and average slagging is established. And a slagging stability index with a ratio of the maximum slagging fluctuation and average slagging is presented. Meanwhile, a cutting efficiency index by the weighed average value of multistage rock fragmentation of a cutter's specific energy is established. The Robbins and China Railway Construction Corporation (CRCC) cutterheads are evaluated. The results show that under the same thrust and torque, the slagging stability of the CRCC scheme is worse, but the slagging continuity of the CRCC scheme is better. The cutting ability index shows that the CRCC cutterhead is more efficient.
\end{abstract}

Keywords: Evaluation of cutterhead, Cutting ability, Slagging ability, Rock fragmentation load

\section{Introduction}

A full-face rock tunnel boring machine (TBM) is a kind of large-scale construction machinery specially used for excavation of underground passage works. It is used widely in subway, railway, highway, municipal, and hydropower projects [1]. It has the advantages of fast excavation, high quality, safety, economy, environmental protection, and reduced labor intensity [2]. The cutterhead system is the core working part of full-face rock TBM, which breaks the rock and supports the tunnel face. The TBM cutterhead is a key component affecting driving performance and efficiency [3]. The evaluation of tunneling performance is an important basis for the design of the cutterhead. TBM tunneling efficiency parameters include driving speed, construction schedule, cutter wear, and machine utilization rate [4]. At present,

\footnotetext{
*Correspondence: zhuye198727@163.com

${ }^{1}$ School of Mechanical and Engineering, Dalian Jiaotong University, Dalin 116000, China

Full list of author information is available at the end of the article
}

scholars have proposed a variety of prediction models, including a single-factor prediction model, a comprehensive prediction model, and a fuzzy neural network model. The single-factor prediction model is aimed only at driving speed. On the basis of the data of hard rock (uniaxial compressive strength is 140-200 MPa), Graham [5] proposed the prediction equation of driving speed. On the basis of the data of sedimentary rock, Farmer et al. [6] proposed the prediction equation of driving speed. Hughes [7] presented the forecasting equation of tunneling speed; Nelson [8] predicted an equation for TBM performance in shales, sandstones, and limestones; and O'Rourke [9] predicted equations based on metamorphic data. The Norwegian University of Science and Technology [10] proposed the Norwegian Institute of Technology (NTNU) prediction model, an empirical model of the TBM that covers driving speed, wear of the cutters, utilization rate of the boring machine, and cost estimation. The Colorado School of Mines (CSM) [11] proposed a comprehensive prediction model based on the measurement of the cutters thrust in different types of rock. 
Xia et al. $[12,13]$ studied the performance of cutter ring under different working conditions. Entacher et al. [14, 15] studied the changing law of cutter load by installing sensors on cutter for different tunneling and analysis. Hassanpour et al. [16] developed new equations to predict the performance of hard-rock TBMs in carbonateargillaceous rocks. Gehring [17] conducted research on the influence of TBM design and machine features on performance and tool wear in rock. Hamidi et al. [18] also conducted performance prediction of hard-rock TBMs using the rock mass rating system. Hassanpour et al. [19] introduced a regression model for hard-rock TBM performance prediction. Farrokh et al. [20] studied various models used to estimate the penetration rate of hard-rock TBMs. Moradi and Farsangi [21] predicted the advance rate in rock TBM tunneling using the risk matrix method. Ghasemi et al. [22] developed a fuzzy logic model to predict the penetration rate of hard-rock TBM based on rock properties. This algorithm provides an iterative method that simulates mass interactions, and it moves through a multidimensional search space under the influence of gravitation. Huo et al. [23-26] studied on the vibration of the TBM cutter head and the fatigue damage of the cutter head under the multi space load. Tao et al. [27] described a hybrid approach that integrates all kinds of investigation methods in real and virtual environments to evaluate the sitting posture comfort in a human-vehicle system. Wang et al. [28] proposed a novel wheel rum center method to evaluate suspension performance.

Scholars mainly used the field test, the similar model test, and numerical simulation and other technical means to study the rock fragmentation mechanism, the breaking random load, and the plane layout of the cutters. The evaluation of cutterheads, however, lacks a systematic and comprehensive theoretical approach, a specific index, and an index of calculation model, which evaluates primarily from a single aspect but with comprehensive multiple factors. Therefore, this paper built a systematic multihierarchical evaluation system of TBM cutterheads and individually completed an evaluation of each index, which provided a theoretical foundation to improve the driving speed, prolong cutter life, and reduced the cost of TBM.

\section{Configuration Performance Evaluation System of TBM Cutterheads}

\subsection{Performance Evaluation Model}

A reasonable performance evaluation of TBM cutterhead is of great importance to improve driving speed, improve the life of the cutterhead and cutters, reduce mining cost, and reduce the vibration of the boring machine. To establish a better performance evaluation system of the cutterhead, scholars toured the construction site and enterprise to understand the failure of the TBM cutterhead during construction as well as the requirements and difficulties faced in manufacturing. As shown in Figure 1, construction tunneling and slagging was found to be the main function of the TBM cutterhead, and these two functions directly affect the cutterhead's efficiency and service life. According to this situation, this paper takes cutting efficiency, slagging efficiency, and slagging stability as indexes to establish a multihierarchical evaluation system, as shown in Figure 2.

\subsection{Evaluation of Cutterhead Slagging Ability}

The mucking slot needs to discharge broken rock debris in a timely fashion. The unreasonable design of mucking slots can lead to discharge capacity failing to meet broken rock volume requirements, which causes rock ballast to continuously accumulate in the driving interface, leading to the cutterhead not working normally. Because the rock ballast is produced in the excavation process in discrete blocks, its mechanical characteristics are different from the conventional research objects in mechanical engineering research. Thus, it is difficult to simulate the TBM tunneling process through common finite element software, such as ANSYS, DYNAFORM, and ABAQUS. According to the characteristics of discontinuous medium, we study the dynamics and kinematics behavior of the mucking slot using the discrete element software PFC3D.

During the TBM cutterhead process, because of the limitation of the cutterhead space and the rotation of the cutterhead, it is impossible for mucking slots to achieve continuous slag discharge. This causes the driving interface to always have residual rock slag, which in turn makes contact continuously with the cutterhead surface and cutters. This severe contact may cause wear of the cutterhead surface and abnormal damage to the cutters. Timely rock slag discharge is relevant to the degree of fluctuation of the amount of the rock slag. As noted, TBM cutterhead slagging performance should follow two evaluation criteria: slagging continuity and slagging stability.

\subsubsection{Slagging Continuity Criteria}

In the process of TBM, the amount of broken rock in unit time is $Q_{B}(t)$, and the amount of slagging in unit time is $Q_{D}(t)$. So, the discharging efficiency is the ratio of the maximum difference between slagging amount and tunneling amount and average slagging:

$$
C_{D E}=\Delta Q_{\max } / \overline{Q_{D}}
$$




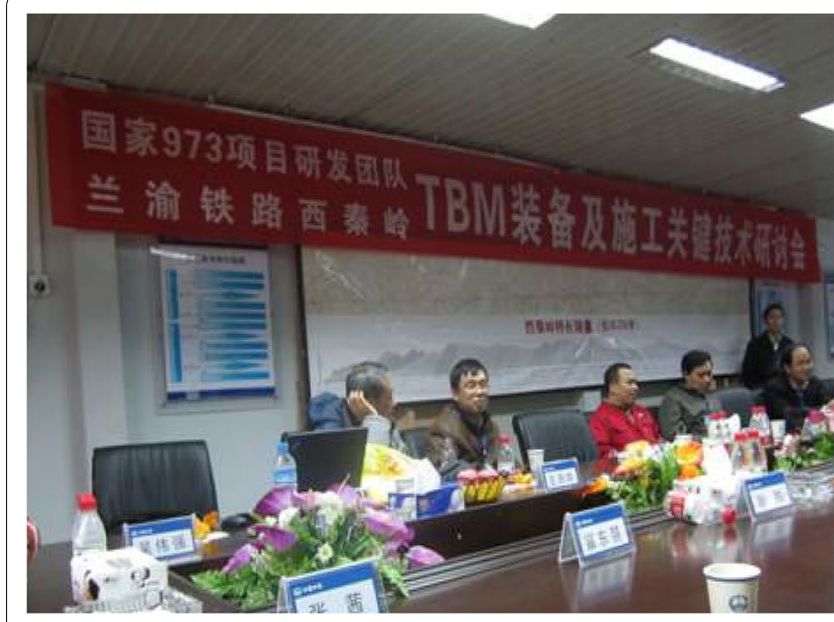

a Lan Yu Railway research in 2012

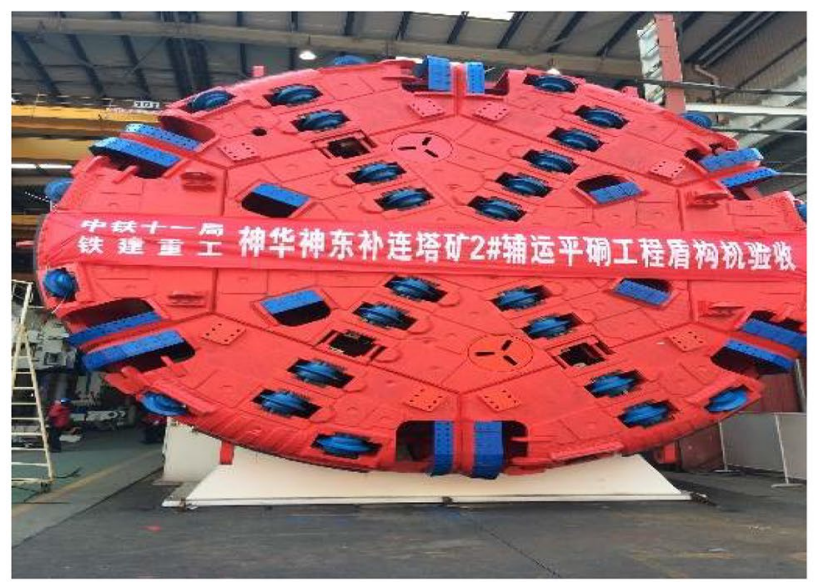

c China Railway Equipment Co., Ltd. research in 2014

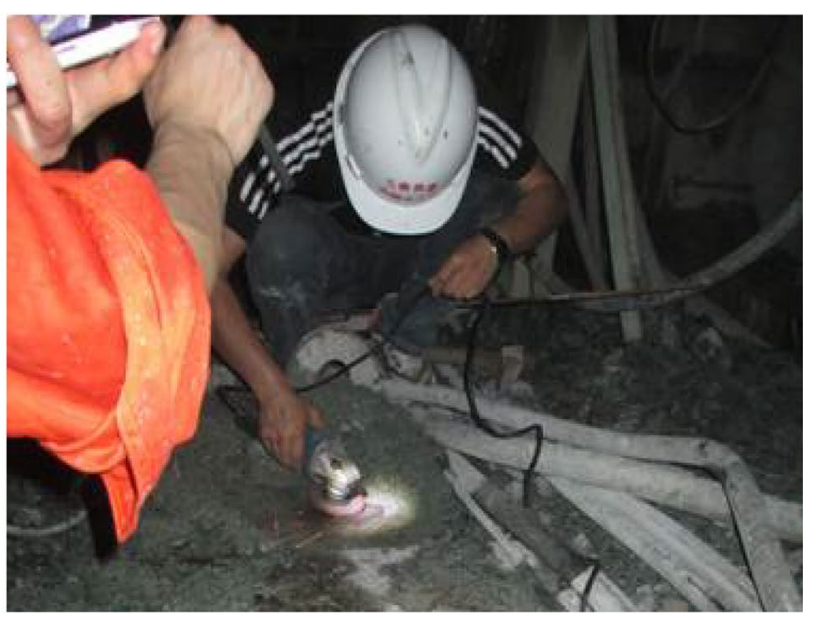

b West Qinling Mountains tunnel research in 2013

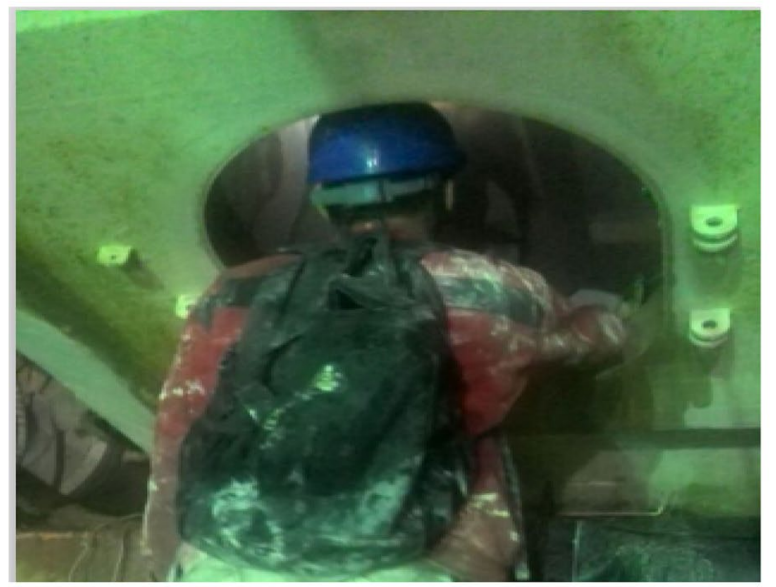

d Jilin Yinsong Engineering Research in 2015

Figure 1 Manufacturing enterprises and construction site research experience

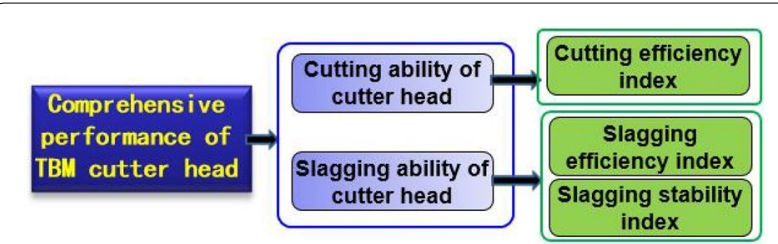

Figure 2 Performance evaluation system of the TBM cutterhead

$$
\Delta Q_{\max }=\max \left(Q_{D}(t)-Q_{B}(t)\right) .
$$

In the tunneling process of TBM, the whole cutterhead advances forward, but the area of the tunneling face and the cutterhead surface remains basically the same. Therefore, the amount of rock breaking in the unit time can be calculated by the following formula:

$$
Q_{B}=\frac{\lambda \pi D^{2} h v_{r}}{4},
$$

where $\lambda$ is loose square coefficient of rock, $D$ is the diameter of TBM cutterhead, $v_{r}$ is the revolving speed TBM cutterhead, and $h$ is penetration of TBM cutterhead.

$$
h=\frac{v}{v_{r}}
$$

where $v$ is the driving speed of the cutterhead.

\subsubsection{Slagging Stability Criteria}

When the amount of broken rock is constant, the maximum slagging in unit time is $Q_{D \max }(t)$, the minimum slagging in unit time is $Q_{D \max }(t)$, and the average unit slagging is $\bar{Q}_{D}(t)$. So, the slagging stability index is the ratio of the 
maximum slagging fluctuation and the average slagging, as follows:

$$
C_{\Delta D}=\frac{Q_{D \max }(t)-Q_{D \min }(t)}{\bar{Q}_{D}(t)} .
$$

\subsection{Evaluation of Cutterhead Cutting Ability}

\subsubsection{Evaluation Model of Cutting Efficiency}

TBM tunneling efficiency determines whether the method is economical and reasonable, and whether it can be used for rapid excavation. Therefore, the evaluation of the tunneling efficiency is an important basis for cutterhead design. The energy consumption of the cutter is an important parameter to evaluate the cutting ability of the TBM cutterhead. In this paper, we use the average specific energy of the whole process of the cutting rock as the index of cutting efficiency.

Gertsch and Ozdemir have studied the breaking specific energy and proposed the simplified formula for calculation of specific energy [29]:

$$
S E=\frac{E}{V}=\frac{F_{R} d}{S P d}=\frac{F_{R}}{S P}=\frac{F_{R}}{A},
$$

where $F_{R}$ is rolling force, $S$ is cutter spacing, $P$ is cutting depth, $d$ is rolling distance, and $A$ is rock crushing area below the cutter.

It is evident that the key to calculating the cutting specific energy by Eq. (6) is to accurately predict the amount of rock breaking and the load of the hobbing cutter in the process of crushing rock. Because of changes in the amount of rock breaking and the load of the hob during the rock-breaking process, in the past, the formula used to calculate rock-breaking load has not reflected the problem. In this paper, on the basis of dense core theory, we summarize a multicutter rock-breaking process and establish the compound space rock fragmentation load prediction of the cutter group, which provides the theoretical basis to calculate the evaluation index according to the actual situation of the TBM cutterhead. The specific process is shown in Figure 3.

According to the actual situation of the knife dish, this paper proposes an evaluation model of the cutting efficiency evaluation index. We established the cutterhead's cutting efficiency evaluation index based on the weighed average value of the specific energy of cutters under the condition of the whole tunnel. We evaluate the cutting ability of the TBM cutterhead, as shown in Eq. (7):

$$
C_{S E}=\overline{S E}=\sum_{i=1}^{n} \xi_{i}\left(\sum_{j=1}^{m} n_{j} \overline{S E_{i j}} / \sum_{j=1}^{m} n_{j}\right),
$$

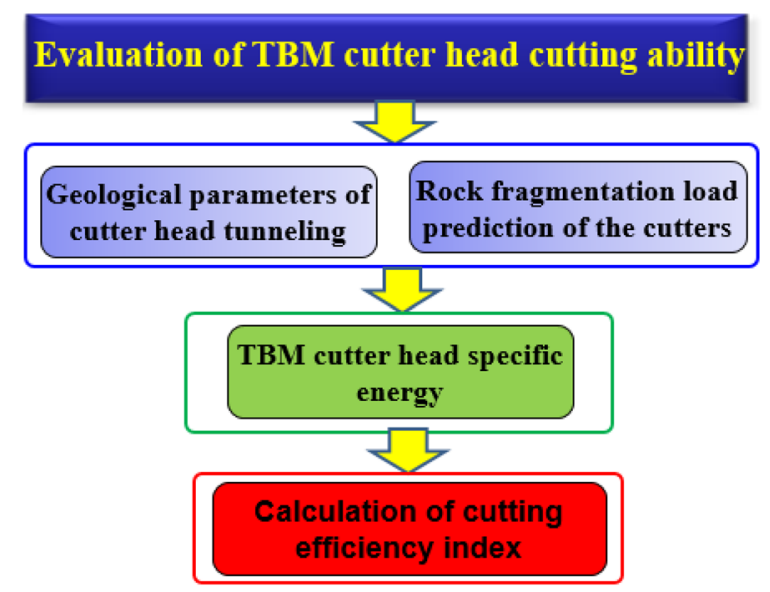

Figure 3 Flow diagram of cutting ability

where $\xi_{i}$ is the proportion of rock and soil in the whole tunnel, $\mathrm{m}$ is the number of types of cutter, $\mathrm{n}$ is the number of each cutter, and $\overline{S E_{i j}}$ is the entire rock breaking stage of the average.

In the process of rolling rock with disc cutters, vertical force is much larger than rolling force, but its work distance is small. Generally, the cutter thrust specific energy is ignored, and the rock-breaking specific energy of the cutter is primarily the rolling ratio energy. Thrust is an important factor in determining the specific energy of the cutter. Under the action of a small thrust, the rock will not be broken, and then the research of specific energy would be meaningless.

\subsubsection{Multistage Space Rock Fragmentation Load Prediction of the Cutter Group}

To accurately calculate the energy consumption of the cutters, an accurate model of the cutter's stress is needed. The TBM cutterhead is equipped with different types of cutting tools. According to the different installation positions, they can be divided into center cutter, inner cutter, and gauge cutter. The center cutter is located in the center of the cutterhead, the outward position is the inner cutter, and the gauge cutter. The layout of different types of disc cutters on the cutterhead is shown in Figure 4. For the TBM cutter, the load is different according to the different parameters, such as the cutter installation method. The parameters influencing force $F$ include the cutter structure parameters (the blade width $T$, cutter radius $R$, the blade angle $\theta$ ), cutter layout parameters (cutter spacing $S$, installation radius $\rho$, phase angle difference of adjacent cutter $\alpha$, installation angle $\beta$ ), driving parameter (blade penetration depth $h$, speed $n$, driving speed $v$, cutter and rock contact angle $\varphi$ ), and rock 


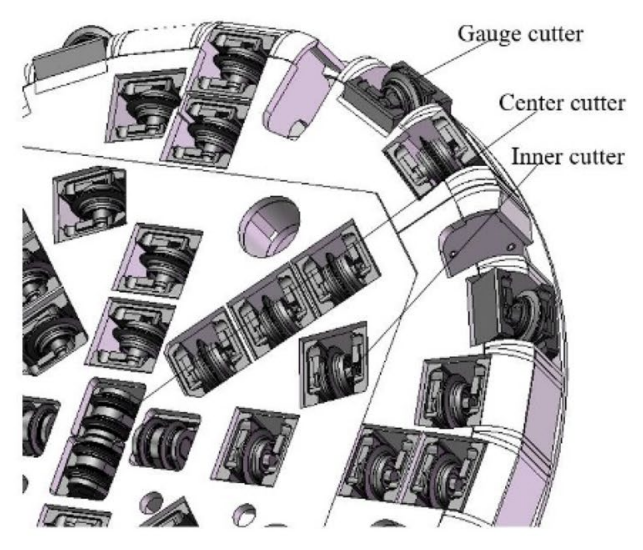

a The cutter layout of cutterhead
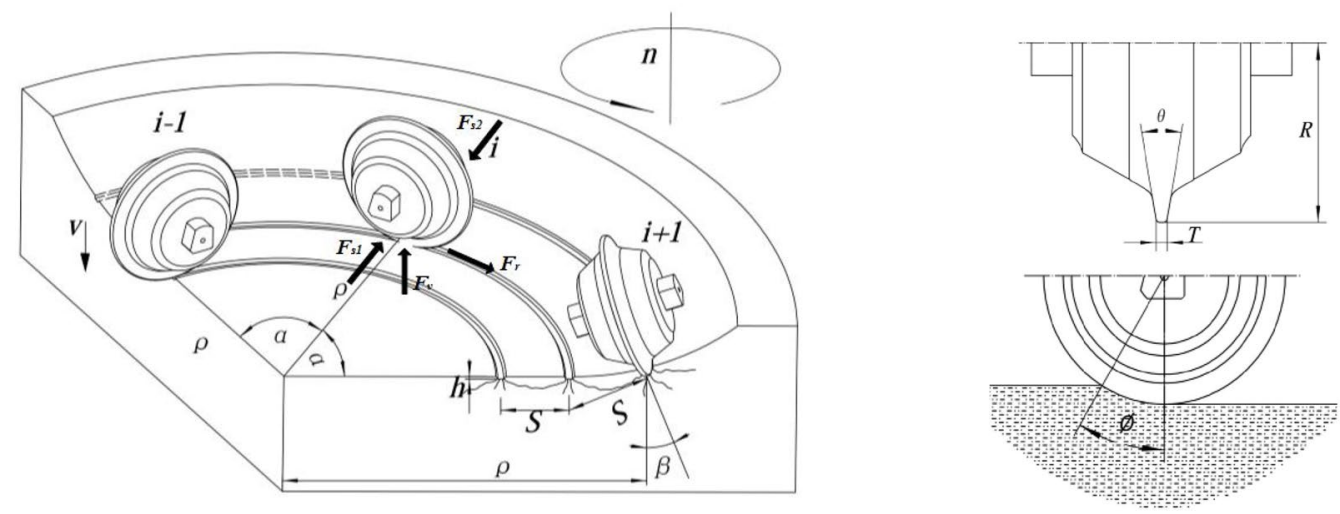

b Rock fragmentation model by disc cutter

Figure 4 Disc cutter layout of the cutterhead and the rock fragmentation model cut by disc cutter

characteristics (uniaxial compressive strength $\sigma_{c}$, shear strength $\sigma_{t}$ ). That is,

$$
F=f\left(T, R, \theta, S, r, \alpha, \beta, \varphi, h, \omega, \nu, \sigma_{c}, \sigma_{t}\right) .
$$

According to the different installation angles, the force prediction model is divided into two categories: the compound multistage space-breaking force prediction model of the inner cutter and the center cutter, and the compound multistage space-breaking force prediction model of the gauge cutter.

(1) Load prediction model of the inner cutter and center cutter

In the elastic deformation stage, the pressed depth of the blade is small, which can be approximated as a rectangle. The contact area of rock is shown in Figure 5, and the rectangular area is calculated as follows:

$$
A=R \varphi\left(T+2 h \tan \frac{\theta}{2}\right)
$$

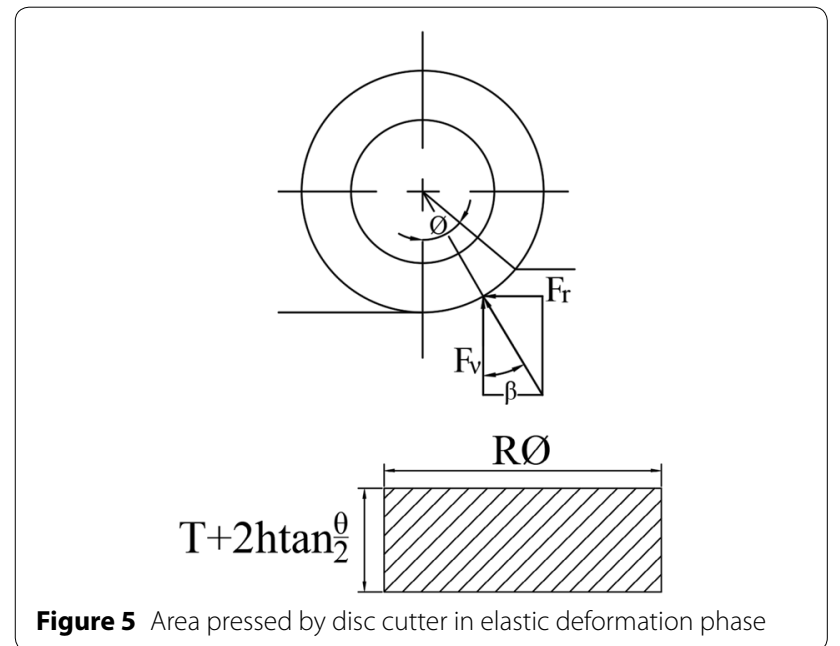

$$
F_{v}=\sigma_{s} A=\frac{1}{k} \sigma_{c} \sqrt{2 R h}\left(T+2 h \tan \frac{\theta}{2}\right) .
$$


where $k$ is the elastic limit coefficient; for the rock, and $k$ $=1.5-3$.

In the extrusion crushing state, when the load continues to be applied, the force of the rock beneath the cutter head is greater than the uniaxial compressive strength, so the rock vertically below the cutter is crushed. Considering that the flat blade cutter is used widely in engineering, we provide a cutter mechanical model that considers confining pressure. The projection area in the rock surface of the area in which the disc cutter is fixed to the rock is shown in Figure 6. The crushed rock area is calculated as follows:

$$
A=R \varphi\left(T+h \tan \frac{\theta}{2}\right)
$$

where the contact arc length between the cutter and the rock is approximately equal to the chord length, as shown:

$$
R \varphi \approx \sqrt{R^{2}-(R-h)^{2}+h^{2}}=\sqrt{2 R h},
$$

and the vertical and rolling force are, respectively,

$$
\begin{aligned}
& F_{\nu}=\sigma_{c} A=\sigma_{c} \sqrt{2 R h}\left(T+h \tan \frac{\theta}{2}\right), \\
& F_{r}=F_{\nu} \tan \varphi=\sigma_{c}\left(T+h \tan \frac{\theta}{2}\right) \sqrt{2 R h} \cdot \frac{\sqrt{2 R h-h^{2}}}{R-h} .
\end{aligned}
$$

The force on the front of cutter tip $F_{3}$ is the component force of $F_{r}^{\prime}$ in the direction of the cutter shaft, and the lateral force $F_{s}$ is as follows:

$$
\begin{aligned}
F_{s} & =F_{r}^{\prime} \sin \beta=F_{r} \frac{\rho_{i}}{\sqrt{\rho_{i}^{2}+(R \sin \varphi)^{2}}} \cdot \frac{R \sin \varphi}{\sqrt{\rho_{i}^{2}+(R \sin \varphi)^{2}}} \\
& =\frac{F_{r} \sqrt{2 R h-h^{2}}}{\rho_{i}^{2}+2 R h-h^{2}} .
\end{aligned}
$$

In the crack coalescence stage, the dense nucleus stage is divided into two main parts: the dense nucleus compaction process and the crack extension instability

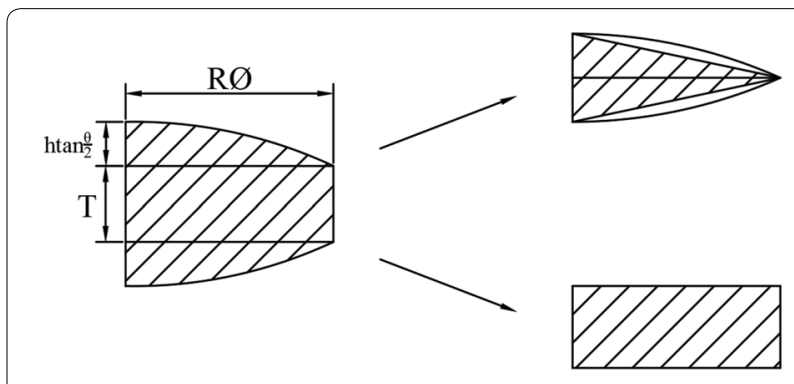

Figure 6 Area pressed by disc cutter in squeezing crushing phase process. In the dense nucleus compaction process, the contact area between the dense nucleus and the rock is almost the same, and lateral surrounding rocks are broken. Therefore, the lateral force cannot be calculated with the shear strength of rock.

Before rock damage around the dense nucleus occurs, the contact area between the dense nucleus and the rock is a half circle (Figure 7), and the contact area is calculated as follows:

$$
A=\frac{1}{2} \pi T R \varphi=\frac{1}{2} \pi T \sqrt{2 R h} .
$$

Vertical force is calculated as follows:

$$
F_{v}=\frac{1}{2} \sigma_{c} \pi T \sqrt{2 R h}
$$

In the process of compaction, the vertical load $F$ of the cutter is equal to the resultant force of rock reaction force $F_{1}$ and the component force of rock reaction force $F_{2}$ on both sides of the blade in the vertical direction, as shown in Figure 8. That is,

$$
F_{v}=F_{1}+2 F_{2} \sin \frac{\theta}{2} .
$$

Because the dense nucleus is in hydrostatic pressure, the pressure around the dense nucleus is the same. That is, the area corresponding to $F_{1}, F_{2}$ is as follows:

$$
\begin{aligned}
\frac{F_{1}}{A_{1}} & =\frac{F_{2}}{A_{2}}, \\
A_{1} & =T R \varphi \approx T \sqrt{2 R h}, \\
A_{2} & =\frac{1}{2} R^{2} \varphi-\frac{1}{2}(R-h) \sqrt{2 R h-h^{2}} \\
& =\frac{1}{2} R \sqrt{2 R h}-\frac{1}{2}(R-h) \sqrt{2 R h-h^{2}} .
\end{aligned}
$$

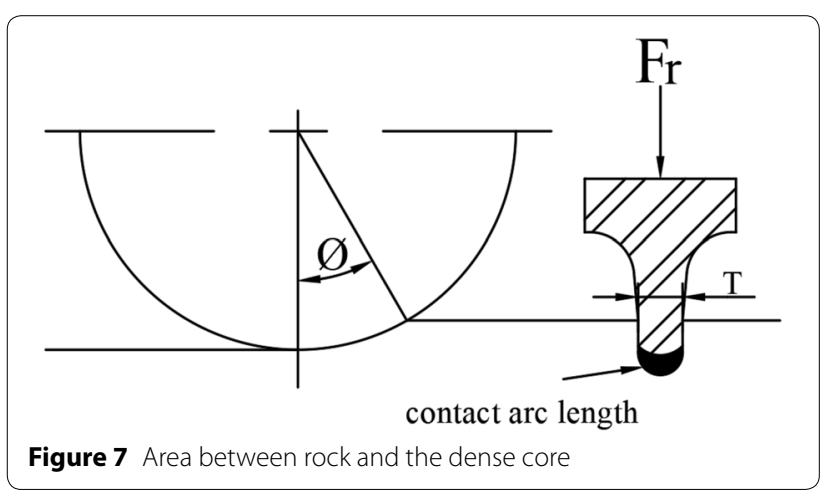




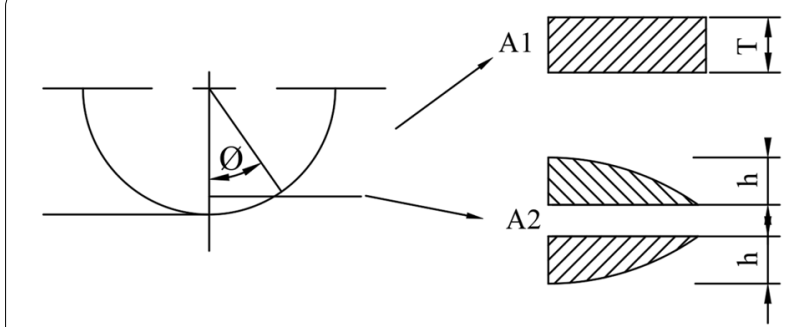

Figure 8 Area between the blade and the side of rock

The relationship between the load $F_{v}$ of the cutter and the hydrostatic pressure $P$ is as follows:

$$
\begin{aligned}
F_{v} & =\frac{T \sqrt{2 R h}}{\frac{1}{2} R \sqrt{2 R h}-\frac{1}{2}(R-h) \sqrt{2 R h-h^{2}}} F_{2}+2 \sin \frac{\theta}{2} F_{2} \\
& =P \cdot A=\frac{1}{2} P \pi T \sqrt{2 R h},
\end{aligned}
$$

where $P$ is the pressure of dense nucleus per unit area. In the process of compaction, the numerical value of $P$ is increasing, and when $P \geq f(S) \sigma_{c}$, the rock reaches the uniaxial compressive strength and is broken. The vertical force is calculated as follows:

$$
F_{v}=\left[\frac{T \sqrt{2 R h}}{\frac{1}{2} R \sqrt{2 R h}-\frac{1}{2}(R-h) \sqrt{2 R h-h^{2}}}+2 \sin \frac{\theta}{2}\right] F_{2} .
$$

Rolling force $F_{r}$ is calculated as follows:

$$
F_{r}=F_{\nu} \tan \varphi=\frac{1}{2} \sigma_{c} \pi T \sqrt{2 R h} \cdot \frac{\sqrt{2 R h-h^{2}}}{R-h} .
$$

When the cutter is rolling in a straight line, the lateral force is the component force of $F_{2}$ in the horizontal, that is,

$$
F_{2}^{\prime}=\frac{F_{v}\left[\frac{1}{2} R \sqrt{2 R h}-\frac{1}{2}(R-h) \sqrt{2 R h-h^{2}}\right]}{\sqrt{2 R h}\left(T+R \sin \frac{\theta}{2}\right)-\sin \frac{\theta}{2}(R-h) \sqrt{2 R h-h^{2}}} \cos \frac{\theta}{2} .
$$

The lateral stress $F_{3}$ of the cutter tip is the component force of $F_{r}$ in the direction of the cutter shaft, that is,

$$
\begin{aligned}
F_{3} & =F_{r}^{\prime} \sin \beta=F_{r} \frac{\rho_{i}}{\sqrt{\rho_{i}^{2}+(R \sin \varphi)^{2}}} \cdot \frac{R \sin \varphi}{\sqrt{\rho_{i}^{2}+(R \sin \varphi)^{2}}} \\
& =\frac{F_{r} \sqrt{2 R h-h^{2}}}{\rho_{i}^{2}+2 R h-h^{2}} .
\end{aligned}
$$

When the strength of the rock is not the same, the lateral force is the difference between $F_{2}^{\prime}$ and $F_{3}$. Therefore,

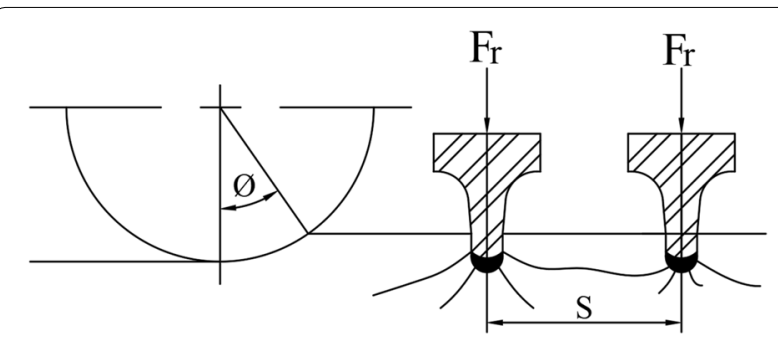

Figure 9 Area of side force

the lateral force is the resultant force of rock pressure $F_{2}^{\prime}$ exerted by the cutter blade angle and the component force of rolling force $F_{3}$ in the cutter shaft direction. So, the lateral force $F_{s}$ follows:

$$
\begin{aligned}
F_{s}= & F_{3} \pm F_{2}^{\prime}=\frac{F_{r} \sqrt{2 R h-h^{2}}}{\rho_{i}^{2}+2 R h-h^{2}} \\
& \pm \frac{F_{v}\left[\frac{1}{2} R \sqrt{2 R h}-\frac{1}{2}(R-h) \sqrt{2 R h-h^{2}}\right]}{\sqrt{2 R h}\left(T+\frac{R}{2} \sin \frac{\theta}{2}\right)-\sin \frac{\theta}{2}(R-h) \sqrt{2 R h-h^{2}}} \cos \frac{\theta}{2} .
\end{aligned}
$$

When the rock is in the process of crack growth, the rock on both sides of the cutter can reach the shear limit and can be broken, as shown in Figure 9. The contact area of the lateral force follows:

$$
A=\left(S-2 h \tan \frac{\theta}{2}\right) R \varphi=\sqrt{2 R h}\left(S-2 h \tan \frac{\theta}{2}\right) .
$$

At this point, the lateral force $F_{s}$ calculation formula is as follows:

$$
F_{s}=\sigma_{t} A=\sigma_{t} \sqrt{2 R h}\left(S-2 h \tan \frac{\theta}{2}\right) .
$$

Because the crack on both sides of the cutter is completely through, the rock-breaking area is

$$
A=h S .
$$

(2) Gauge cutter multistage spatial load forecasting model

In the elastic deformation stage, the depth contact between the rock and the gauge cutters is small, so the area can be approximately equal to the contact area between the rock and the center cutter, and the calculation formula is same as that of center cutter.

In the extrusion crushing stage, because the driving direction of the gauge cutter and the installation direction have a certain angle, the contact part of the cutter and the rock can be seen as the wedge edge, as shown in Figure 10. Therefore, the crushed rock area is calculated as follows: 


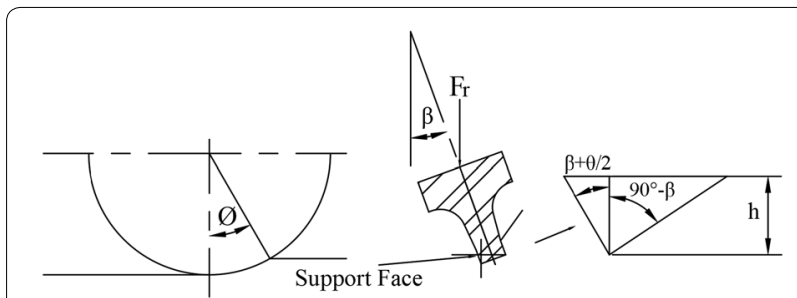

Figure 10 Contact area

$$
\begin{aligned}
A & =\frac{1}{2} R \varphi h\left[\tan \left(90^{\circ}-\beta\right)+\tan \left(\beta+\frac{\theta}{2}\right)\right] \\
& =\frac{1}{2} h \sqrt{2 R h}\left[\tan \left(90^{\circ}-\beta\right)+\tan \left(\beta+\frac{\theta}{2}\right)\right],
\end{aligned}
$$

when $h=T \cos \left(90^{\circ}-\beta\right)$, the area reaches its maximum.

So, the vertical force of the cutter is

$$
\begin{aligned}
F_{v} & =\sigma_{c} A \cos \beta \\
& =\frac{1}{2} \sigma_{c} h \sqrt{2 R h}\left[\tan \left(90^{\circ}-\beta\right)+\tan \left(\beta+\frac{\theta}{2}\right)\right] \cos \beta .
\end{aligned}
$$

The lateral force is

$$
\begin{aligned}
F_{s} & =\sigma_{c} A \sin \beta \\
& =\frac{1}{2} \sigma_{c} h \sqrt{2 R h}\left[\tan \left(90^{\circ}-\beta\right)+\tan \left(\beta+\frac{\theta}{2}\right)\right] \sin \beta,
\end{aligned}
$$

with geometric relation, the rolling force is

$$
F_{r}=F_{v} \tan \varphi=F_{v} \sqrt{2 R h} \cdot \frac{\sqrt{2 R h-h^{2}}}{R-h} .
$$

In the crack coalescence stage, before the destruction of the surrounding rock, the contact area between the rock and dense nucleus is shown in Figure 11 and is calculated as follows:

$$
\begin{aligned}
A_{1} & =\frac{1}{2} \pi R \varphi T \cos \left(90^{\circ}-\beta\right)\left[\tan \left(90^{\circ}-\beta\right)+\tan \left(\beta+\frac{\theta}{2}\right)\right] \\
& =\frac{1}{2} \pi T \cos \left(90^{\circ}-\beta\right) \sqrt{2 R h}\left[\tan \left(90^{\circ}-\beta\right)+\tan \left(\beta+\frac{\theta}{2}\right)\right] .
\end{aligned}
$$

Vertical force is calculated as follows:

$$
\begin{aligned}
F_{v} & =\sigma_{c} A_{1} \cos \beta \\
& =\frac{1}{2} \pi \sigma_{c} T \cos \left(90^{\circ}-\beta\right) \sqrt{2 R h} \\
& \times\left[\tan \left(90^{\circ}-\beta\right)+\tan \left(\beta+\frac{\theta}{2}\right)\right] \cos \beta .
\end{aligned}
$$

Because the gauge cutter is located at the edge of the cutterhead, the influence of the installation radius on the

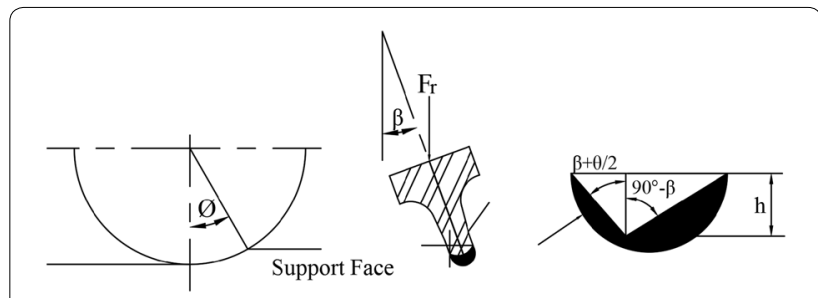

Figure 11 Area between dense core and rock of gauge cutter

lateral force can be neglected. Therefore, the lateral force calculation method of the gauge cutter is different from the center cutter. As the contact depth increases, the side of the cutter is constantly exposed to the new rock, and there is no dense core. The rock still has a side shear, however, and the area of this part is calculated as follows:

$$
\begin{aligned}
A_{2}= & {\left[S-2 h \tan \left(\beta+\frac{\theta}{2}\right)\right] } \\
& \cdot R \varphi\left[h-T \cos \left(90^{\circ}-\beta\right)\right] \tan \left(\beta+\frac{\theta}{2}\right) \\
= & {\left[S-2 h \tan \left(\beta+\frac{\theta}{2}\right)\right] } \\
& \cdot \sqrt{2 R h}\left[h-T \cos \left(90^{\circ}-\beta\right)\right] \tan \left(\beta+\frac{\theta}{2}\right) .
\end{aligned}
$$

The lateral force is the resultant force, that is,

$$
\begin{aligned}
F_{s}= & \sigma_{c} A_{1} \sin \beta+\sigma_{t} A_{2} \\
= & \frac{1}{2} \sigma_{c} T \cos \left(90^{\circ}-\beta\right) \sqrt{2 R h} \\
& \times\left[\tan \left(90^{\circ}-\beta\right)+\tan \left(\beta+\frac{\theta}{2}\right)\right] \sin \beta \\
& +\sigma_{t}\left[S-2 h \tan \left(\beta+\frac{\theta}{2}\right)\right] \sqrt{2 R h} \\
& \times\left[h-T \cos \left(90^{\circ}-\beta\right)\right] \tan \left(\beta+\frac{\theta}{2}\right) .
\end{aligned}
$$

The rolling force is

$$
F_{r}=F_{v} \tan \varphi=F_{v} \sqrt{2 R h} \cdot \frac{\sqrt{2 R h-h^{2}}}{R-h} .
$$

At this point, the rock-breaking area is

$$
A=h S \text {. }
$$

When the tilt angle is less than the blade angle $\theta$, both sides of the rolling blade are involved in the rock breaking. The extent of the break is different and the influence is break, and therefore it is calculated according to the two inner cutters. 
(3) Overall model

In view of the different rock properties, we consider cutter structure parameters, layout, and the tunneling parameters. The rock-breaking process is divided into four stages: an elastic deformation stage, an extrusion crushing stage, a crack coalescence stage, and an unloading stage. We then deduce the compound multistage space-breaking load prediction models of the cutters in different position.

For the inner cutter and center cutter, the vertical force is

$F_{v}= \begin{cases}\frac{1}{k} \sigma_{c} \sqrt{2 R h}\left(T+2 h \tan \frac{\theta}{2}\right), & \text { elastic deformation stage, } \\ \sigma_{c} \sqrt{2 R h}\left(T+h \tan \frac{\theta}{2}\right), & \text { extrusion crushing stage, } \\ \frac{1}{2} \sigma_{c} \pi T \sqrt{2 R h}, & \text { crack coalescence stage. }\end{cases}$

The lateral force is

$$
S E=\frac{F_{r}}{A}= \begin{cases}\frac{2 \sigma_{c}\left(T+2 h \tan \frac{\theta}{2}\right) \sqrt{2 R h} \cdot \sqrt{2 R h-h^{2}}}{k h\left[\tan (90-\beta)+\tan \left(\beta+\frac{\theta}{2}\right)\right] R-h}, & \text { elastic deformation stage, } \\ \sigma_{c} \cos \beta \cdot \sqrt{2 R h} \cdot \frac{\sqrt{2 R h-h^{2}}}{R-h}, & \text { extrusion deformation stage, } \\ \frac{\pi \sigma_{c} T R \sqrt{2 R h} \cdot \cos (90-\beta) \cdot \cos \beta \cdot\left[\tan (90-\beta)+\tan \left(\beta+\frac{\theta}{2}\right)\right] \sqrt{2 R h-h^{2}}}{S \cdot(R-h)}, & \text { crack coalescence stage. }\end{cases}
$$

The specific energy of the gauge cutter is calculated as follows:

$$
F_{S}= \begin{cases}0, & \text { elastic deformation stage, } \\ \frac{F_{r} \sqrt{2 R h-h^{2}}}{\rho_{i}^{2}+2 R h-h^{2}}, & \text { extrusion crushing stage, } \\ \frac{F_{r} \sqrt{2 R h-h^{2}}}{\rho_{i}^{2}+2 R h-h^{2}} \pm \frac{F_{v}\left[\frac{1}{2} R \sqrt{2 R h}-\frac{1}{2}(R-h) \sqrt{2 R h-h^{2}}\right]}{\sqrt{2 R h}\left(T+\frac{R}{2} \sin \frac{\theta}{2}\right)-\sin \frac{\theta}{2}(R-h) \sqrt{2 R h-h^{2}}} \cos \frac{\theta}{2}, & \text { dense nuclear stage, } \\ \sigma_{t} \sqrt{2 R h}\left(S-2 h \tan \frac{\theta}{2}\right), & \text { rack coalescence stage. }\end{cases}
$$

The rolling force is

$$
F_{r}=F_{v} \sqrt{2 R h} \cdot \frac{\sqrt{2 R h-h^{2}}}{R-h} .
$$

For the gauge cutter, the vertical force is

$$
F_{v}= \begin{cases}\frac{1}{k} \sigma_{c} \sqrt{2 R h}\left(T+2 h \tan \frac{\theta}{2}\right), & \text { elastic deformation stage, } \\ \frac{1}{2} \sigma_{c} h \sqrt{2 R h}\left[\tan \left(90^{\circ}-\beta\right)+\tan \left(\beta+\frac{\theta}{2}\right)\right] \cos \beta, & \text { extrusion deformation stage, } \\ \frac{1}{2} \pi \sigma_{c} T \cos \left(90^{\circ}-\beta\right) \sqrt{2 R h} \cdot\left[\tan \left(90^{\circ}-\beta\right)+\tan \left(\beta+\frac{\theta}{2}\right)\right] \cos \beta, & \text { crack coalescence stage. }\end{cases}
$$

The lateral force is

$$
F_{s}=\left\{\begin{array}{l}
0, \\
\frac{1}{2} \sigma_{c} h \sqrt{2 R h}\left[\tan \left(90^{\circ}-\beta\right)+\tan \left(\beta+\frac{\theta}{2}\right)\right] \sin \beta, \\
\frac{1}{2} \sigma_{c} T \cos \left(90^{\circ}-\beta\right) \sqrt{2 R h}\left[\tan \left(90^{\circ}-\beta\right)+\tan \left(\beta+\frac{\theta}{2}\right)\right] \sin \beta+\sigma_{t} \sqrt{2 R h} \\
\times\left[S-2 h \tan \left(\beta+\frac{\theta}{2}\right)\right]\left[h-T \cos \left(90^{\circ}-\beta\right)\right] \tan \left(\beta+\frac{\theta}{2}\right),
\end{array}\right.
$$

3 Engineering Project

We evaluated the driving performance of the two TBM cutterheads in the Liaoning Water Northwest Water Diversion Tunnel Project and Jilin Water Diversion Project under the same geological conditions: the Robbins 


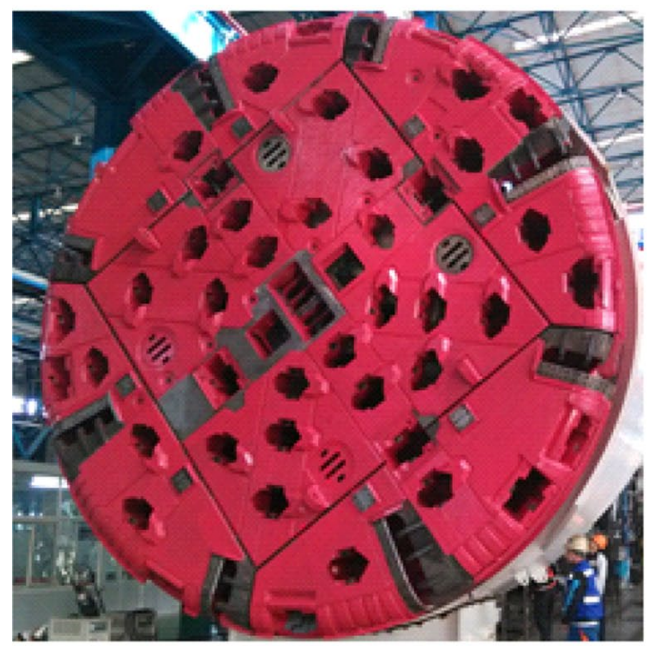

a Robbins $\phi 8.53 \mathrm{~m}$ TBM cutterhead

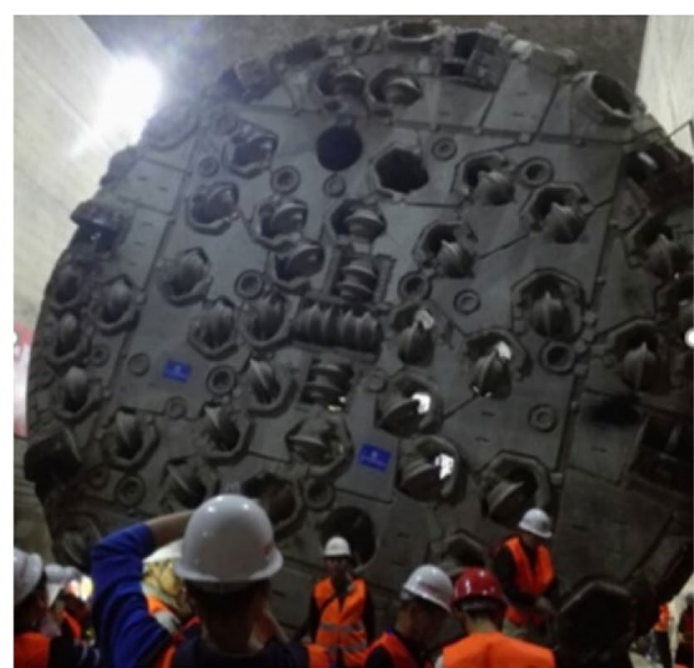

b CRCC $\phi 7.83 \mathrm{~m}$ TBM cutterhead

Figure 12 TBM cutterheads service in Liaoning northwest

$\phi 8.53 \mathrm{~m}$ (Figure 12a) and the China Railway Construction Corporation (CRCC) $\$ 7.8 \mathrm{~m}$ (Figure 12b). The Liaoning Northwest Water Diversion Tunnel Project geological conditions are given in Table 1.

The Liaoning Northwest Water Diversion Tunnel Project is located in northern Shenyang. This area is drought prone, and the Liaoning Diversion Project was developed to address water problems in the region [26]. The main physical parameters of the two kinds of rock strata are given in Table 1 . The tunneling speed in the Migmatite is $2.6 \mathrm{~m} / \mathrm{h}$, and the rotation speed of the cutterhead is $6.26 \mathrm{r} / \mathrm{min}$. In the Giant, the driving speed is $1.5 \mathrm{~m} / \mathrm{h}$, and the rotation speed of the cutterhead is $5.6 \mathrm{r} / \mathrm{min}$.

\subsection{Evaluation Instance of Slagging Ability}

Figures 13 and 14 provide a discrete element simulation (simulation software: PFC.5.0) of the TBM cutterhead and the accompanying results.

According to calculation results from Eqs. (1) and (5), the index values of the slagging ability evaluation of the two cutterheads are given in Table 2.

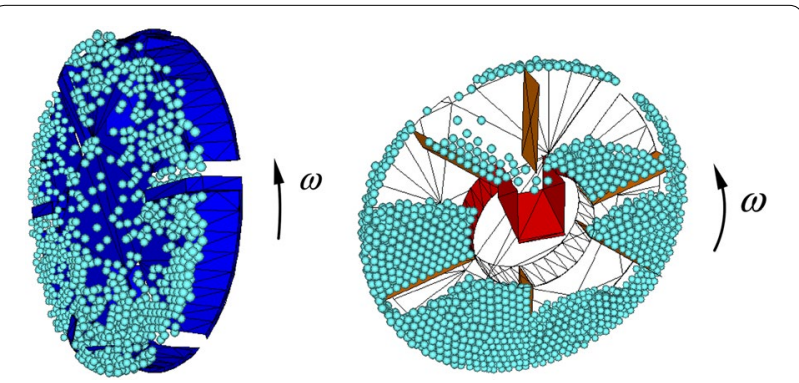

Figure 13 Discrete element simulation of TBM cutter head

Slagging continuity and slagging stability have differences of $2.8 \%$ and $26.6 \%$, respectively. These results show that the slagging ability of the two cutterheads is similar, that the slagging stability of CRCC scheme is worse, and that the slagging continuity of the CRCC scheme is better.

Table 1 Physical parameters of two kinds of rock

\begin{tabular}{|c|c|c|c|c|c|c|c|c|c|c|}
\hline $\begin{array}{l}\text { Stratigraphic } \\
\text { code }\end{array}$ & $\begin{array}{l}\text { Stratum } \\
\text { rock }\end{array}$ & $\begin{array}{l}\text { Dry } \\
\text { density } \\
\left(\mathrm{g} / \mathrm{cm}^{3}\right)\end{array}$ & $\begin{array}{l}\text { Natural } \\
\text { density } \\
\left(\mathrm{g} / \mathrm{cm}^{3}\right)\end{array}$ & $\begin{array}{l}\text { Specific } \\
\text { gravity }\end{array}$ & $\begin{array}{l}\text { Natural } \\
\text { water } \\
\text { absorption } \\
\text { rate }(\%)\end{array}$ & $\begin{array}{l}\text { Saturated } \\
\text { water } \\
\text { absorption } \\
\text { rate }(\%)\end{array}$ & $\begin{array}{l}\text { Longitudinal } \\
\text { wave speed } \\
\text { of rock }(\mathrm{m} / \mathrm{s})\end{array}$ & $\begin{array}{l}\text { Elasticity } \\
\text { modulus } \\
(\mathrm{GPa})\end{array}$ & $\begin{array}{l}\text { Poisson } \\
\text { ratio } \mu\end{array}$ & $\begin{array}{l}\text { Proportion } \\
\text { of the whole } \\
\text { tunnel (\%) }\end{array}$ \\
\hline Pt1x & $\begin{array}{l}\text { Migma- } \\
\text { tite }\end{array}$ & 2.71 & 2.72 & 2.74 & 0.28 & 0.30 & 4500 & 80 & 0.15 & 11 \\
\hline Pt1S & Giant & 2.66 & 2.67 & 2.68 & 0.23 & 0.26 & 5000 & 55 & 0.20 & 89 \\
\hline
\end{tabular}




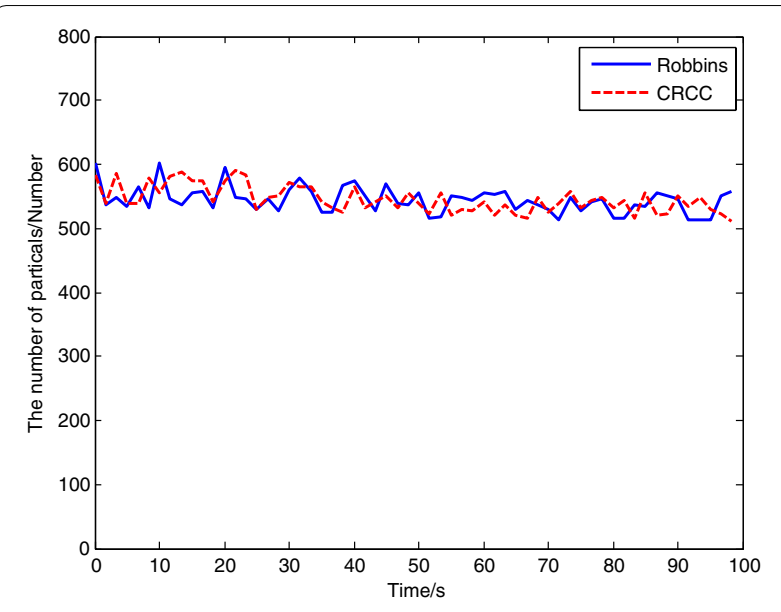

a Variation of slugging fluctuation with time

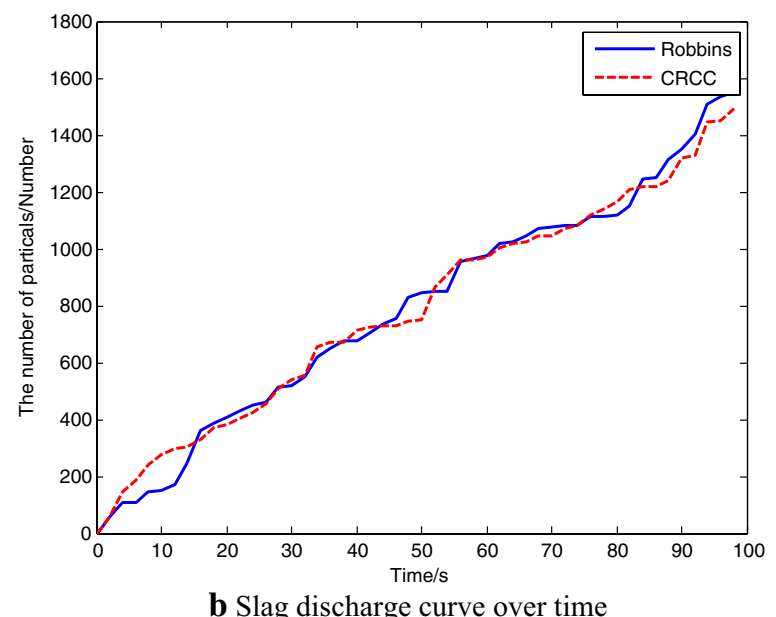

Figure 14 Discrete element simulation results

\subsection{Evaluation Instance of Cutting Ability}

Table 3 gives the main parameters of the Robins and CRCC cutterheads. Table 4 gives the energy consumption of the two cutterheads in the two kinds of rock strata.

According to the previous parameters, and the different rock-breaking stage corresponding to the different penetration, we obtain the cutting efficiency and related parameters of the two cutterheads and combine these parameters with Eqs. (6), (7), (47), and (48).

As shown in Table 5, when the two programs have the same thrust and torque, even with different cutter spacing, the efficiency difference is $10 \%$. This finding demonstrates that the CRCC cutterhead has a more reasonable design in regards to cutting efficiency.

\section{Table 2 Evaluation of cutterhead slagging performance}

\begin{tabular}{lll}
\hline TBM cutterhead performance index & CRCC scheme & Robbins scheme \\
Slagging ability & & \\
Slagging continuity index & 0.153 & 0.125 \\
Slagging stability index & 0.883 & 0.617 \\
\hline
\end{tabular}

\section{Conclusions}

This paper presents a multilevel evaluation system for the performance of TBM cutterheads. Using Robbins and CRCC TBM cutterheads as examples, the specific conclusions drawn are as follows.

(1) According to the specific situation of the former project, we established a comprehensive performance evaluation system of a TBM cutterhead and proposed the calculation method of each index to evaluate the performance of TBM cutterhead for cutting ability and slagging ability.

(2) We established the compound multistage rockbreaking load prediction model of the cutter group. multistage rock fragmentation of a cutter's specific energy. On the basis of the dense core theory and different rock conditions, we analyzed the multistage rock-breaking process of the multicutter and established the compound multistage space rock fragmentation load prediction model of the cutter group.

(3) The evaluation results of the slagging ability of Robbins and CRCC TBM cutterheads show that slagging continuity and slagging stability have differences of $2.8 \%$ and $26.6 \%$, respectively. These results show that the slagging stability of CRCC scheme is worse, although its slagging speed is slightly higher than the Robbins scheme. The layout of Robbins scheme is more efficient for slagging stability.

(4) As with cutting efficiency, when the two programs have the same thrust and torque, but different cutter spacing, the efficiency difference is $10 \%$, which shows that the CRCC cutterhead has a more reasonable design.

(5) Though a basis for the overall performance evaluation of TBM cutterhead is provided, these two indicators alone are not enough to fully evaluate the overall performance of it. Stiffness, strength and other indicators of the cutterhead should also be considered. 
Table 3 Main parameters of two TBM cutterheads

\begin{tabular}{lllllllll}
\hline TBM cutterhead & $\begin{array}{l}\text { Center cutter } \\
\text { radius }(\mathbf{m m})\end{array}$ & $\begin{array}{l}\text { Normal and gauge } \\
\text { cutter radius }(\mathbf{m m})\end{array}$ & $\begin{array}{l}\text { Blade } \\
\text { width } \\
(\mathbf{m m})\end{array}$ & $\begin{array}{l}\text { Included } \\
\text { angle } \boldsymbol{\theta}\end{array}$ & $\begin{array}{l}\text { Cutterhead } \\
\text { diameter } \\
(\mathbf{m m})\end{array}$ & $\begin{array}{l}\text { Cutter } \\
\text { spacing } \\
(\mathbf{m m})\end{array}$ & $\begin{array}{l}\text { Migmatite } \\
\text { penetration } \\
(\mathbf{m m})\end{array}$ & $\begin{array}{l}\text { Granite } \\
\text { penetration } \\
(\mathbf{m m})\end{array}$ \\
\hline Robbins & 195 & 216 & 19.25 & 20 & 8.53 & 90 & 6.92 & 4.46 \\
CRCC & 195 & 216 & 19.25 & 20 & 7.8 & 83 & 6.92 & 4.46 \\
\hline
\end{tabular}

Table 4 Energy consumption of rock cutting

\begin{tabular}{|c|c|c|c|c|}
\hline Rock type & Cutterhead & $\begin{array}{l}\text { Average breaking specific } \\
\text { energy of center cutter }\left(\mathrm{J} / \mathrm{m}^{3}\right)\end{array}$ & $\begin{array}{l}\text { Average breaking specific } \\
\text { energy of normal cutter }\left(\mathrm{J} / \mathrm{m}^{3}\right)\end{array}$ & $\begin{array}{l}\text { Average breaking specific } \\
\text { energy of gauge cutter }(\mathrm{J} / \\
\left.\mathrm{m}^{3}\right)\end{array}$ \\
\hline \multirow[t]{6}{*}{ Migmatite } & $\begin{array}{l}\text { Robbins } \\
\text { Elastic deformation stage }\end{array}$ & $2.81 \times 10^{5}$ & $2.72 \times 10^{5}$ & $3.32 \times 10^{5}$ \\
\hline & Extrusion crushing stage & $1.66 \times 10^{6}$ & $1.63 \times 10^{6}$ & $1.71 \times 10^{6}$ \\
\hline & Crack coalescence stage & $3.62 \times 10^{6}$ & $3.51 \times 10^{6}$ & $3.90 \times 10^{6}$ \\
\hline & $\begin{array}{l}\text { CRCC } \\
\text { Elastic deformation stage }\end{array}$ & $2.81 \times 10^{5}$ & $2.72 \times 10^{5}$ & $3.10 \times 10^{5}$ \\
\hline & Extrusion crushing stage & $1.66 \times 10^{6}$ & $1.63 \times 10^{6}$ & $1.65 \times 10^{6}$ \\
\hline & Crack coalescence stage & $3.26 \times 10^{6}$ & $3.16 \times 10^{6}$ & $3.34 \times 10^{6}$ \\
\hline \multirow[t]{6}{*}{ Granite } & $\begin{array}{l}\text { Robbins } \\
\text { Elastic deformation stage }\end{array}$ & $2.54 \times 10^{5}$ & $2.43 \times 10^{5}$ & $5.01 \times 10^{6}$ \\
\hline & Extrusion crushing stage & $1.48 \times 10^{6}$ & $1.44 \times 10^{6}$ & $1.77 \times 10^{6}$ \\
\hline & Crack coalescence stage & $3.32 \times 10^{6}$ & $3.15 \times 10^{6}$ & $3.61 \times 10^{6}$ \\
\hline & $\begin{array}{l}\text { CRCC } \\
\text { Elastic deformation stage }\end{array}$ & $2.54 \times 10^{5}$ & $2.43 \times 10^{5}$ & $2.87 \times 10^{5}$ \\
\hline & Extrusion crushing stage & $1.48 \times 10^{6}$ & $1.44 \times 10^{6}$ & $1.56 \times 10^{6}$ \\
\hline & Crack coalescence stage & $2.99 \times 10^{6}$ & $2.83 \times 10^{6}$ & $3.10 \times 10^{6}$ \\
\hline
\end{tabular}

Table 5 Cutting efficiency of two cutterheads

\begin{tabular}{lllll}
\hline Cutterhead & $\begin{array}{l}\text { Number } \\
\text { of center } \\
\text { cutter }\end{array}$ & $\begin{array}{l}\text { Number } \\
\text { of normal } \\
\text { cutter }\end{array}$ & $\begin{array}{l}\text { Number } \\
\text { of gauge } \\
\text { cutter }\end{array}$ & $\begin{array}{l}\text { Cutting } \\
\text { efficiency } \\
\left(\mathbf{J} / \mathbf{m}^{\mathbf{3}}\right)\end{array}$ \\
\hline Robbins & 8 & 35 & 11 & $1.67 \times 10^{6}$ \\
CRCC & 8 & 32 & 11 & $1.49 \times 10^{6}$ \\
\hline
\end{tabular}

\section{Authors' Contributions}

$Y Z$ was in charge of the whole trial and wrote the manuscript; WS and $J \mathrm{H}$ and ZM assisted with sampling and laboratory analyses. All authors read and approved the final manuscript.

\section{Authors' Information}

Ye Zhu received $\mathrm{PhD}$ degree in engineering from School of Mechanical and Engineering, Dalian University of Technology China, in 2019, His research interests include performance evaluation of large equipment and Fatigue life prediction of large equipment.

Wei Sun received PhD degree in engineering from School of Mechanical and Engineering, Dalian University of Technology, China, in 2000. Now he is a professor at School of Mechanical and Engineering, Dalian University of Technol ogy, China. His main research domains include design and optimization of complex mechanical equipment, mechanical transmission and structure CAD/ CAE
Junzhou Huo received his $\mathrm{PhD}$ degree in engineering from School of Mechanical and Engineering, Dalian University of Technology, China, in 2007, Now he is an Associate Professor at School of Mechanical and Engineering, Dalian University of Technology, China. His main research domains include performance optimization of Complex mechanical system performance optimization.

Zhichao Meng born in Shanxi Province in 1995, is currently a master candidate at School of Mechanical Engineering, Dalian University of Technology, China.

\section{Competing Interests}

The authors declare no competing financial interests.

Funding

Supported by National basic research program of China (973 Project, Grant No. 2013CB035400), National Natural Science Foundation of China (Grant No. 51375001), Major Projects of Liaoning Science and Technology Plan (Grant No. 2015106016) and Basic Research Project of Central University (Grant No. DUT16QY11).

Author Details

1 School of Mechanical and Engineering, Dalian Jiaotong University, Dalin 116000, China. ${ }^{2}$ School of Mechanical and Engineering, Dalian University of Technology, Dalian 116000, China.

Received: 15 January 2019 Accepted: 14 November 2019

Published online: 05 December 2019 


\section{References}

[1] Qijun Zhang, Zhonghai Zhang, Hong Zhang. Approach of tunnel TBM technology and market demand in China. Trenchless Technology, 2003(4): 76-80.

[2] Qihu Qian, Zhaofu Li, Deming Fu. The present and prospect of application of tunneler in China's underground engineering. Underground Space, 2002, 22(1): 1-11.

[3] H Haeri, M F Marji. Simulating the crack propagation and cracks coalescence underneath TBM disc cutters. Arabian Journal of Geosciences, 2016, 9(2): 1-10.

[4] J Huo, W Wang, W Sun, et al. The multi-stage rock fragmentation load prediction model of tunnel boring machine cutter group based on dense core theory. International Journal of Advanced Manufacturing Technology, 2016: 1-13.

[5] P C Graham. Rock exploration for machine manufacturers. Exploration for Rock Engineering, 1976: 173-180.

[6] I W Farmer, N H Glossop. Mechanics of disc cutter penetration. Tunne/s and Tunnelling, 1980, 12(6): 22-25.

[7] H M Hughes. The relative cuttability of coal-measures stone. Mining Science and Technology, 1986, 3(2): 95-109.

[8] P Nelson. Tunnel boring machine performance in sedimentary rock. 1983.

[9] J E O'Rourke, J E Springer, S V Coudray. Geotechnical parameters and tunnel boring machine performance at Goodwin tunnel, California. North American Rock Mechanics Symposium, 1994.

[10] J Rostami. Development of a force estimation model for rock fragmentation with disc cutters through theoretical modeling and physical measurement of crushed zone pressure. Colorado School of Mines, 1997.

[11] G L Dollinger, H J Handewith, C D Breeds. Use of the punch test for estimating TBM performance. Tunnelling \& Underground Space Technology, 1998, 13(4): 403-408.

[12] X Zhang, Y Xia, Y Zhang, et al. Experimental study on wear behaviors of TBM disc cutter ring under drying, water and seawater conditions. Wear, 2017: 392-393.

[13] Y Xia, Y Tian, Q Tan, et al. Side force formation mechanism and change law of TBM center cutter. Journal of Central South University, 2016, 23 : 1115-1122.

[14] M Entacher, G Winter, T Bumberger, et al. Cutter force measurement on tunnel boring machines-System design. Tunnelling and Underground Space Technology, 2012, 31: 97-106.

[15] M Entacher, G Winter, R Galler. Cutter force measurement on tunne boring machines-Implementation at Koralm tunnel. Tunnelling and Underground Space Technology, 2013, 38: 487-496.

[16] J Hassanpour, J Rostami, M Khamehchiyan, et al. Developing new equations for TBM performance prediction in carbonate-argillaceous rocks: a case history of Nowsood water conveyance tunnel. Geomechanics \& Geoengineering an International Journal, 2009, 4(4): 287-297.

[17] D I Mont. The influence of TBM design and machine features on performance and tool wear in rock. Geomechanik Und Tunnelbau, 2009, 2(2): 140-155.

[18] J K Hamidi, K Shahriar, B Rezai, et al. Performance prediction of hard rock TBM using Rock Mass Rating (RMR) system. Tunnelling \& Underground Space Technology, 2010, 25(4): 333-345

[19] J Hassanpour, J Rostami, J Zhao. A new hard rock TBM performance prediction model for project planning. Tunnelling \& Underground Space Technology, 2011, 26(5): 595-603.

[20] E Farrokh, J Rostami, C Laughton. Study of various models for estimation of penetration rate of hard rock TBMs. Tunnelling \& Underground Space Technology, 2012, 30(4): 110-123.

[21] M R Moradi, M A E Farsangi. Application of the risk matrix method for geotechnical risk analysis and prediction of the advance rate in rock TBM tunneling. Rock Mechanics \& Rock Engineering, 2014, 47(5): 1951-1960.

[22] E Ghasemi, S Yagiz, M Ataei. Predicting penetration rate of hard rock tunnel boring machine using fuzzy logic. Bulletin of Engineering Geology \& the Environment, 2014, 73(1): 23-35.

[23] Junzhou Huo, Dong Zhu, Guangqing Li, et al. Application of a small-timescale fatigue, crack-growth model to the plane stress/strain transition in predicting the lifetime of a tunnel-boring-machine cutter head. Engineering Failure Analysis, 2017, 71: 11-30.

[24] Junzhou Huo, Nan Hou, Wei Sun, et al. Analyses of dynamic characteristics and structure optimization of tunnel boring machine cutter system with multi-joint surface. Nonlinear Dynamics, 2017, 87(1): 237-254.

[25] Junzhou Huo, Hanyang Wu, Jing Yang, et al. Multi-directional coupling dynamic characteristics analysis of TBM cutterhead system based on tunnelling field test. Journal of Mechanical Science and Technology, 2015, 29(8): 3043-3058

[26] Junzhou Huo, Xiaolong Sun, Guangqing LI, et al. Multi-degree-offreedom coupling dynamic characteristic of TBM disc cutter under shock excitation. Journal of Central South University, 2015, 22(9): 3326-3337.

[27] Q Tao, J Kang, W Sun, et al. Digital evaluation of sitting posture comfort in human-vehicle system under Industry 4.0 framework. Chinese Journal of Mechanical Engineering, 2016, 29(6): 1096-1103.

[28] W Bo, H Guan, Pingping Lu, et al. Novel evaluation method of vehicle suspension performance based on concept of wheel turn center. Chinese Journal of Mechanical Engineering, 2015, 28(5): 935-944.

[29] M Entacher, E Schuller, R Galler. Rock failure and crack propagation beneath disc cutters. Rock Mechanics and Rock Engineering, 2015, 48(4): 1559-1572.

\section{Submit your manuscript to a SpringerOpen ${ }^{\circ}$ journal and benefit from:}

- Convenient online submission

- Rigorous peer review

- Open access: articles freely available online

- High visibility within the field

Retaining the copyright to your article

Submit your next manuscript at springeropen.com 